\title{
ENTREVISTA AO PROF. DR. FRANCISCO DE OLIVEIRA: ENTRE CONTROVÉRSIAS E CONTRADIÇÕES DA SOCIEDADE BRASILEIRA
}

\author{
Lidiane M. Maciel* \\ Sara Freitas **
}

\begin{abstract}
A figura simpática e polêmica do Prof. Francisco de Oliveira, comumente referenciado apenas "Chico de Oliveira" não passa despercebida no âmbito da academia brasileira. Formado em Ciências Sociais pela Universidade Federal de Pernambuco (1956), com especialização em Desenvolvimento Econômico pelo Banco do Nordeste do Brasil (1956), e doutorado em Sociologia pela Universidade de São Paulo (1992), o Professor Francisco de Oliveira dispensa apresentações devido sua importância no cenário do pensamento social brasileiro. Dificilmente um aluno de Ciências Sociais, pelo menos uma vez durante seus estudos não tenha tido contato com uma ou outra obra do autor. Alguns textos do mesmo, como "A critica a razão dualista" publicado em 1973 pelo então, recém-fundado, Cebrap é considerado um clássico no debate sobre desenvolvimentismo no Brasil. Destaca-se também em seu currículo a importância que teve na atuação e implantação da SUDENE juntamente com o economista Celso Furtado, e na criação do Cenedic - Centro de Estudos dos direitos da Cidadania na Universidade de São Paulo.
\end{abstract}

\footnotetext{
* Mestre em sociologia pela Universidade Estadual de Campinas, e doutorada pela mesma Universidade.

** Mestre em sociologia pela Universidade de São Paulo e doutorada pela Universidade de Campinas.
} 
Numa manhã, fria e cinzenta de setembro, em São Paulo, o Prof. Chico de Oliveira nos recebeu em seu apartamento e simpaticamente nos concedeu a entrevista aqui publicada, nela o Professor explora questões de cunho conjunturais e históricas da formação da sociedade brasileira, também nos apresenta o nordeste dos tempos atuais, e rememora sua trajetória intelectual dentro do Cenedic, por fim, também se posiciona em relação à política brasileira nos tempos atuais, assunto que tem sido um de seus preferidos nos últimos tempos. A Idéias - Revista do Instituto de Filosofia e Ciências Humanas - agradece ao Prof. Chico de Oliveira pela disposição em nos receber, e convida nossos leitores a apreciação da entrevista que segue. 
Revistas Idéias: Professor como visto em outras entrevistas ${ }^{1}$, o senhor tende a conceber o nordeste não mais como uma região, então, o que seria o nordeste hoje? Considerando sua experiência de atuação na SUDENE ${ }^{2}$, pensando também que o nordeste não é mais o grande problema do Brasil, visto que as periferias de São Paulo ou Rio Janeiro são tão problemáticas e pobres quanto a Região, haveria ainda disputas internas na "Região", por exemplo, entre os Estados mais ricos Bahia, Pernambuco e Ceará, podemos ainda pensarmos em uma política de desenvolvimento e integração?

Chico de Oliveira: Não é mais politica de desenvolvimento, agora você repare que as disputas recaem sobre as empresas, a integração já houve, o que não quer dizer que há uma homogeneização do espaço econômico nacional. Em nenhuma parte do mundo esse processo é visto, salve alguns países da Europa, que tem havido um desenvolvimento que homogeneizou toda a região, mesmo assim se você verificar vai encontrar muitas diferenças que são interessantes, a França é um país que parece muito homogêneo, mas há diferenças que compõem as regiões, a Alemanha também, mas aquela parte que foi a República Democrática, menos desenvolvida, os Estados Unidos é a mesma coisa, não há homogeneização completa. O Brasil não é exceção houve integração, no sentido de que os ciclos econômicos obedecem à mesma lógica, uma empresa não vai para o nordeste mais pensando que vai dominar aquele mercado e o subdesenvolvimento sendo sua defesa, então você pode citar casos de empresas e isso encontra uma política de governadores que tenta manter os incentivos "puxando a brasa para sua sardinha", mas com um enorme esforço e gastando os recursos de seu Estado, ai você pode citar empresas, e isso é sinal de integração.

\footnotetext{
${ }^{1}$ Como em: RIDENTI, M, S. e MENDES, S, F. Do dualismo ao ornitorrinco: entrevista com Francisco de Oliveira. In: CADERNO CRH, Salvador, v. 25, 66, p. 601-622, Set./Dez. 2012.

${ }^{2}$ Superintendência do Desenvolvimento do Nordeste, criada em 1959.
} 
Revista Idéias: Considerando essa política empresarial da qual o senhor fala, qual é o impacto para os trabalhadores? Quando as empresas saem do sudeste e vão para o Nordeste, por exemplo...

Chico de Oliveira: Esse é um dos pontos que as empresas aproveitam, a organização dos trabalhadores é mais precária do que no sudeste, e eles não tem o grau de organização que se tem no sudeste, isso ainda atua como um benefício para as empresas que vão para lá, mas também não muito, não é mais como no passado, em que o esforço de integração davam certo, não podemos esquecer que em alguns Estados com em Pernambuco, na área metropolitana do Recife, os trabalhadores tinham uma tradição de organização política, que era mais alta do que em outras regiões do Brasil, mas isso também não ocorre mais, a própria queda dos partidos de esquerda faz com que eles não tenham mais instrumentos políticos, eles não vão brigar com as próprias mãos.

Revista Idéias: E sobre a atuação do Partido Comunista Brasileiro $(P c B)$, o que o senhor fala?

Chico de Oliveira: $O$ partidão era muito forte no Recife e influenciou a esquerda, possibilitou, por exemplo, que Miguel Arraes se elegesse três vezes no Estado de Pernambuco, a última eleição dele ainda estava baseada na memória, já que em décadas anteriores ele dava de "lavada" na oposição, e qual era a diferença em relação aos outros candidatos? Era a base social, formada majoritariamente por trabalhadores, olhando comparativamente com o Brasil, eles eram radicalmente à esquerda.

Revista Idéias: E na Bahia, havia também tamanha organização?

Chico de Oliveira: Não, na Bahia era menos, e em outros estados do Brasil, então, salve o Rio que ainda tinha uma organização política mais consistente, Rio Grande do Sul, com o gauchismo, não havia outros, já São Paulo era relevante por conta da organização dos trabalhadores, a região que nós conhecemos hoje como $\mathrm{ABC}$ 
paulista era uma região "vermelha", todos esses municípios operários eram vermelhos, mas o próprio desenvolvimento operário foi desgastando essas identidades politicas, e hoje se você der um berro perguntando quem ai é do Partido Comunista em São Bernardo você é preso, não pela questão política, mas porque está perturbando a paz pública, as pessoas querem dormir...

Revista Idéias: Podemos falar em uma cultura do individualismo?

Chico de Oliveira: Não chega ser uma cultura do individualismo. $\mathrm{O}$ individualismo no Brasil é pouco fincado em bases sociais, é mais calcado no consumo, não temos uma cultura propriamente individualista no Brasil, ao contrario dos países liberais, o êxito está no ter um emprego.

Revista Idéias: O senhor poderia dizer que há pequenos mecanismos que são gestados no cerne da sociedade geram esse conformismo e amortecem assim o conflito social?

Chico de Oliveira: Há conflitos, mas são de outra natureza hoje, não é mais o político diretamente que está em jogo. $\mathrm{O}$ conflito social dificilmente se transforma em conflito político, deixa rastros, bastante tênues, mas, é de outra natureza, não forma mais consciência política da forma com fez no passado, o fato de São Paulo ter elegido conservadores e reacionários, nos últimos tempos, nos mostra que houve uma mudança na percepção das classes, que continuam sendo classe sociais, em relação à política.

Revista Idéias: Em uma das entrevistas ${ }^{3}$ o senhor disse que o Brasil estava sendo dominado por "gangues" que monopolizam o Estado, que não necessariamente constitui uma classe. Ai, então, teríamos disputas bem definidas dentro do próprio Estado: do empresariado, dos movimentos sociais, dos segmentos que se formam dentro dos partidos, como o senhor vê esse processo?

${ }^{3}$ Roda Viva - Tv Cultura 12 de julho de 2012. 
Chico de Oliveira: O termo gangues eu usei para provocar, mas eles se comportam como verdadeiras gangues e não como partidos políticos, nós temos pedaços do Estado sendo apropriados dentro dos partidos. Agora mesmo um partido como dos Tucanos, a disputa que há entre eles, mostra que a raízes do partido se deram pela à apropriação diferenciada de setores importantes da economia, fazendo, assim, uma política de favores pouco republicana, agora é mais visível, mas é uma coisa que todo mundo já sabia. Eu tive o privilegio de trabalhar no setor de planejamento, que tentava vender seu serviço às empresas, a gente sempre sabia quem dominava as grandes licitações, o jogo de cartas marcadas, é isso que eu digo quando me refiro a comportamento de gangues, no PT também tem.

Revista Idéias: O PT, PSDB, enfim, todos os partidos querem tirar sua fatia de bolo, e isso é um reflexo da sociedade em que vivemos? Como pensá-la hoje? Podemos então considerar que vivemos em uma sociedade autoritária, que guarda muitos resquícios da ditadura? Como poderíamos então questionar o tempo em que vivemos? Como o senhor viu as manifestações de junho de 2013? Há possibilidade de mudança se despontando?

Chico de Oliveira: Eu tendo ser cético, não acho que isso se transformará em movimento político consistente que possa lutar por transformações, foi importante, ninguém suspeitava daquilo, não há nenhum sociólogo que previu que algo como aquilo pudesse ocorrer, mas há um elemento de imediatismo que não transforma o próprio protesto em outra coisa, para isso é preciso termos base social e o que se sabe é que a base social majoritária nessas manifestações não era operaria.

Revista Idéias: Foi dito que os participantes das manifestações eram filhos do que hoje se chama de "Classe média", que acessou a universidade, e bens de consumo, mas que ainda não obtiveram tudo o que lhe fora prometido nos anos recentes pelos governantes... 
Chico de Oliveira: Alguma coisa aconteceu, isso não tenho dúvida, mas acreditar que isso se transforme em um movimento que coloque em cheque algumas estruturas de poder e dominação é um passo largo, eu não acredito que seja uma transformação imediata. Mas também pode ser, pois o que a sociedade tem de interessante é que ela é imprevisível, por mais que nossas ciências tentem acompanhar e prever, o momento da ruptura é imprevisível, não houve nenhum intelectual que previsse as manifestações de junho de 2013, depois das grandes revoluções a gente mitifica a capacidade dos grandes revolucionários de prevê, mas em parte isso é falso. Na revolução russa, uma das últimas grandes revoluções que é nitidamente de classe em abril de 1917, por exemplo, Lênin era reformista, vivia na clandestinidade, se você ler as teses de abril, o último documento dos reformistas, você vê o que aquilo previa constituinte, etc... É a revolução que faz os revolucionários.

\section{Revista Idéias: E a nossa Revolução burguesa?}

Chico de Oliveira: Já se realizou.

\section{Revista Idéias: Pela ditadura?}

Chico de Oliveira: A ditadura foi o golpe final, o que completou, pois em uma revolução nem tudo é uma maravilha, tem sempre seu período violento, no Brasil o período violento dividiu-se em duas partes de 1930 até 37 em que Getúlio Vargas, marcou um período de instabilidade, porém, ele consegue domar as forças revolucionárias tanto de direita quanto de esquerda, ai nós atravessamos um largo período até 1964, quando de novo a sociedade é posta a prova, e há outro período violento que completou a "burguesização" do Brasil, a partir daí você tem a formação de partidos diferenciados por essa áurea revolucionária, o PT, por exemplo, mas na verdade esse nunca foi revolucionário. Os tucanos nem se fale, então nossa sociedade hoje é muito parecida com a de trinta, extremamente modificada pelo desenvolvimento 
econômico, cujo aburguesamento foi completado pela ditadura de 1964, portanto esse período fez o trabalho de parto necessário, então temos uma criança tirada pela metade, ela veio e completouse todas as instituições e estilo de vida atuais são derivadas da fusão de 1930 com 1964.

Revista Idéias: Sobre o esse estilo de vida, quais são os valores que move essa sociedade?

Chico de Oliveira: São valores burgueses, a gente não dá esse nome porque na história real e na história das ideias falar dessa história burguesa é forte, embora a gente tenha. É difícil falar dessa maneira, mas são os valores burgueses que hoje constituem a grande sociedade, o Brasil demorou a ser burguês completamente, mas esses valores burgueses, como eu disse anteriormente, foram completados por 1964.

Revista Idéias: E esses valores o senhor vê que pairam por todas as classes?

Chico de Oliveira: Sim, pairam sob todas as classes.

Revista Idéias: Então, como pensar os "pobres" hoje?

Chico de Oliveira: Os valores dos pobres, por mais contraditório que seja são burgueses, os jovens, por exemplo, buscam o emprego fixo, o que não será mais possível visto a maneira como o capitalismo está se estruturando, estão todos em busca das regalias que todas e quaisquer sociedade burguesa dá a seus membros.

Revista Idéias: Ainda há busca por direito?

Chico de Oliveira: Alguns direitos não são pensados com direitos, se você fizer algumas entrevistas com essa população dificilmente você encontrará como primeira afirmação à busca por 
direitos, assim os direitos também serão pensados com direitos burgueses, e como vocês sabem, direito não é uma coisa natural, eles são uma invenção histórica e social, se vocês fizerem essa pesquisa verão que os direitos aparecerão de uma forma muito enviesada. eles?

Revista Idéias: Não há um reconhecimento da cidadania entre

Chico de Oliveira: Bom, eu não considero nessa postura ai que você fala, essa postura é nossa (sociólogos), eu penso que eles - "os pobres" - podem exercem bem mais que nós, por exemplo, eles podem ser membros do sindicato, do partido, nós da chamada classe média não participamos dessas questões. Mas a questão dos direitos não virá de maneira definida. A questão da cidadania aparece em torno do emprego, sempre o emprego, ele é a via na qual a classe trabalhadora brasileira ascende à cidadania burguesa, e, sobretudo, o que está ficando cada vez mais difícil, eles até acessam a carteira de trabalho, mas os direitos trabalhistas foram destruídos. Tudo gira em torno do registro. A concepção dos direitos começa com a aquisição de uma carteira de trabalho.

Revista Idéias: Sobre essa questão dos direitos, nos fale um pouco da experiência no CENEDIC - Centro de Estudos dos direitos da Cidadania, FFLCH, USP, - a parceria do senhor com o grupo de pesquisa da Profa. Dra. Maria Celia Paoli e a da Profa. Dra. Vera Telles, cujos debates sobre os movimentos sociais foram importantes para as Ciências Sociais brasileiras, e sobre a fase atual do Centro com a saída dessas pesquisadoras e a entrada do Prof. Dr. Rui Braga, e do próprio Prof. Dr. André Singer, também gostaríamos que o senhor falasse mais da política nessa Era de Administração, esses novos pesquisadores acreditam em outras formas da política, o André Singer, por exemplo, acredita nas politicas desenvolvidas pelo Governo Lula, há alguma possibilidade de virada intelectual no Cenedic? 
Chico de Oliveira: Não há de fato uma virada, pois a pessoa que está mais a direita no Núcleo é o André Singer, ele não é de direita, mas é o que está no Cenedic mais a direita, no sentido que ele acha que os mecanismos mais liberais são suficientes para fazer política, mas isso é compensado com a entrada do Rui, ele é decididamente de esquerda, pertence, por exemplo, ao PSTU. O Cenedic hoje é um sujeito a procura de um nome, ele não é mais o que foi com Maria Celia, os debates não tem mais aquela marca, que era muito diferenciada dentro da própria FFLCH ( Faculdade de Filosofia, letras e Ciências Humanas), esse debate chegava a ultrapassar as própria barreiras da FFLCH, hoje não tem mais, hoje é muito mais composição não há uma marca tão marcante, a Maria Celia se afastou, o Laymert também saiu, eu diria que a entrada do André e do Rui, configura de outra maneira o ser do Cenedic, sem que se possa dizer de uma maneira taxativa que o núcleo é direita ou esquerda, não era também porque Maria Célia e Vera estavam mais interessadas nos movimentos sociais e não perceberam que havia uma partidarização dos movimentos sociais, então nós somos hoje um personagem em busca de ator.

Revista Idéias: O que o senhor proporia algo a esse ator?

Chico de Oliveira: Eu não proporia nada, eu acho que está ótimo. O André foi uma excelente aquisição, pois ele é muito bom e leva a política muito a sério e tem um tratamento pessoal que pouco de nós temos, o Ruy tem militância, então ficou ótimo.

Revista Idéias: A partir dos anos 1990 temos uma forte "onguização" da vida pública, e também a entrada do empresariado no jogo. Vejo que quando a sociologia aborda a sociedade civil são os movimentos o grande tema, as ONGs, e o orçamento participativo são abordados parcialmente, porém o empresariado nunca está presente nesse bolo. O empresariado, por exemplo, é sempre lembrado em relação à luta de classe e elite, mas não podemos esquecer que ele hoje através de institutos $e$ associações estão presentes na vida pública, quando não financiando 
ONGs e Movimentos Sociais. No campo da cultura, por exemplo, eu não vou citar aqui o nome...

Chico de Oliveira: Pode citar....

Revista Idéias: O Itaú, por exemplo, tem 26 anos de existência, e se fomos discutir cultura hoje, nós temos do Governo Lula para cá, leis como a Rouanet, não sendo usadas de maneira complementar, mas como a própria política de cultura. E cada vez mais o setor privado vem ocupando o espaço da produção da cultura. Parece-me que o próprio setor empresarial está nessa captura, numa batalha pela construção de uma hegemonia, como o senhor avalia isso? Esse financiamento empresarial na cultura, por exemplo...

Chico de Oliveira: Isso ai decorre do fato de que os partidos políticos não conseguiram fazer essa ponte, digamos que classicamente eles seriam as instituições que apanhariam esses movimentos da sociedade e o transformaria esse movimento em política, os partidos políticos não dão conta disso, então o empresariado percebeu que ai há um buraco enorme e então direcionaram seus esforços, é tudo uma questão de falência das instituições da politica, eles não há o que representar e os partidos não conseguem fazer essa representação. Veja o caso do DEM, que junto com o PT são os mais velhos, da nova safra de partidos, o DEM acabou-se, como é possível pensar que tenha se acabado um partido com bases e programa tão diferenciados do PT? Então acabou-se, ele não é mais nada, meio que jogou um pouco sua herança para os tucanos. E os tucanos que não eram propriamente um partido de direita foram, pela ausência do DEM, empurrados para o centro - não é possível dizer em sã consciência que Fernando Henrique, Zé Serra eram de direita, eles não eram - e o PT mais a esquerda foi sendo também empurrado para o centro, nesse momento nós temos dois partidos de centro, nenhum de esquerda e nenhum de direita.

\section{Revista Idéias: E o PSOL?}


Chico de Oliveira: O PSOL nasceu para fazer a critica ao $\mathrm{PT}$, mas os movimentos sociais que pode lhe dar base já estavam engajados no PT anteriormente, então o PSOL é também um personagem em busca de ator, ele não tem a capacidade agregativa que o PT teve nos seis primeiros anos, ele ficou como um partido que faz a crítica pela esquerda e só.

Revista Idéias: Então, dessa maneira, o senhor acha tem segmentos privados assaltando o Estado? Qual o papel dele nessa nesse cenário?

Chico de Oliveira: O papel do Estado ainda é redistribuir, porém ele muitas vez não cumpre esse papel. Nesse intermédio, ele, digamos não se apropriou dos instrumentos necessários para fazer uma nova política cultural. A cultura é só um exemplo, né? O Estado não criou uma nova forma de atuar, embora seja uma ilusão de ótica, pois na verdade os recursos captados são todos estatais e apropriado pelo setor privado para fazer política cultural, mas o Estado mesmo não desenvolveu novos mecanismos, novas percepções, de como deve fazer cultura para a grande massa. O resumo da opera é que o Estado e os partidos não tem a capacidade, numa sociedade de massa que é a Brasileira, pobre, dirigi-la como uma sociedade de massas, e também não se pode dirigir a ela em termos elitistas, a sociedade é incrível, porque quando você se dirige a ela em termos elitistas ela se transforma em massas, as mais recentes manifestações eram todas de multidão.

Revista Idéias: E, Professor, as manifestações de junho te remeteram então a massas?

Chico de Oliveira: Sim, lembra massa.

Revista Idéias: Nessa ocasião, por exemplo, nós assistimos uma grande recusa a partidos políticos. 
Chico de Oliveira: Mas, mesma a coisa da cultura, o que houve com as grandes multidões? Consumo em massa!

Revista Idéias: Essa recusa das manifestações aos partidos é uma recusa à política?

Chico de Oliveira: É uma recusa à política que configura um paradoxo visto que estavam fazendo política, quando a recusavam. O prefeito de São Paulo na época se mexeu para dar aquilo que parecia ser uma reivindicação do movimento, e na verdade não era, na falta de uma bandeira especifica o movimento congregava todo mundo, pois aquele movimento que saiu às ruas não era só por conta desses vintes centavos, isso não me toca.

Revista Idéias: E o argumento sobre a violência policial que teria reforçado a movimentação em um primeiro momento?

Chico de Oliveira: Não foi isso. Eu repito que isso não me toca, é pouco! A sociedade tem sido como um Rei Midas, ${ }^{4}$ tudo que ela toca vira massa, não há jeito e nem pode, isso não é um sociedade elitista, a gente acusa muito ela de ser elitista, mas não é verdade, a gente é tudo menos elitista, temos alguns setores muito rarefeitos que se apresentam como elitista, mas a nossa sociedade é de massas, e você pode verificar que tudo que tem êxito no Brasil é de massa, senão não cola, não cola e nem aparece. Alguns movimentos são claramente elitistas, por exemplo, a Sala São Paulo ${ }^{5}$, mas te pergunto: Ela é popular? Não, ali realmente é uma coisa de elite.

Revista Idéias: É interessante o espaço onde a Sala São Paulo esta localizada, não é? Pois, a região da Praça Júlio Preste é tomada por uma enorme crackolandia, e então temos uma enorme segregação entre

\footnotetext{
${ }^{4}$ Personagem da mitologia grega.

${ }^{5}$ Sede da Orquestra Sinfônica do Estado de São Paulo - OSEP.
} 
a população que circula ali a noite, principalmente nos finais de semana, ou seja, o público da Sala São Paulo e os moradores da Praça não se tocam.

Chico de Oliveira: Não se tocam, eu mesmo vou de sábado à tarde, e como as outras pessoas eu não quero me misturar com o Crack, aquele espaço é nitidamente elitista. Desconsiderando esse espaço, os outros movimentos na área da cultura não são tocados pelo Rei Midas, não se tornam movimento de massa, o êxito de qualquer movimento no Brasil urbano só se dá se for de massa, se não nem arranha a superfície.

Revista Idéias: E Professor, qual é a pior consequência da formação de uma sociedade de massa no Brasil?

Chico de Oliveira: A pior consequência é que mesmo tendo nos transformados em uma sociedade de massa, mantivemos como base todos os estigmas da desigualdade, ela não dissolveu nenhuma das grandes desigualdades, às vezes nós tendemos a pensar pelo lado do consumo, todo mundo hoje consome todas as coisas que a indústria é capaz de produzir, mas isso é superficial, decisivo é identificar aqueles pontos que não se transformaram ainda em mercado, é isso faz a diferença, qualquer política de Estado que ajude a dissolver os estigmas da longa formação histórica brasileira tem que tocar nas formas que ainda não são necessariamente mercadorias.

Revista Idéias: E questão redistribuir de renda, que hoje se fala, a partir de nossas riquezas naturais, por exemplo, dos Royalties do PréSal que iriam para educação?

Chico de Oliveira: Isso é uma enorme questão e piedosa, você acha mesmo que Petrobras vai distribuir riqueza? Não, ela vai usar isso para se fortalecer no conjunto internacional, e não está interessada em distribuir riqueza. Nós temos uma sociedade que enquanto crescia radicalizou a desigualdade, o capitalismo não tem interesse de reduzir desigualdades, isso já foi, se você lê 
o Manifesto do Partido Comunista ${ }^{6}$, você se surpreenderá que Marx tenha notado um vigoroso processo civilizatório com o capital nos países centrais ao libertar o servo da gleba, processo que nos países da periferia não pode se desenvolver. Quem matou a charada, depois dos grandes clássicos brasileiros foi Florestan Fernandes, ele disse: "Esse país não pode ser democrático porque ele chegou na rabeira do progresso técnico do capitalismo, ele não cria progresso, mas o que é impossível de não fazer, ele cria seu opositor que é o operário", porém, o capitalismo brasileiro não é revolucionário, então como ele trata do proletariado? Ele trata a pau, ou seja, pela violência, ele só pode tratar a pau, pois se não essa criatura vai tomar o lugar dele, isso é Florestan em $A$ revolução Burguesa no Brasil ${ }^{7}$, essa é uma chave explicativa magnífica que nos ajuda entender os esforços interpretativos de Caio Prado e Gilberto Freyre, ele matou a charada ali, então a periferia não pode ser revolucionária.

Revista Idéias: Mas essa periferia da qual o senhor fala convive com o moderno?

Chico de Oliveira: Sim, mas ser moderno não é necessariamente ser revolucionário, ele convive com o revolucionário porque é obrigado.

Revista Idéias: E na visão do senhor como são produzidas as justificativas para essa desigualdade? Pois é, elas são necessárias, não?

Chico de Oliveira: Não, ninguém está preocupado em justificar a desigualdade, isso ai é papo de intelectual.

Revista Idéias: Isso é coisa de sociólogo?

\footnotetext{
${ }^{6}$ MARX, K. \& ENGLES, F. O manifesto do Partido Comunista. São Paulo. Boitempo editorial. 2011 (1848).

${ }^{7}$ FERNANDES, F. A Revolução Burguesa no Brasil: ensaio de interpretação sociológica. Rio de Janeiro: Guanabara, 1987.
} 
Chico de Oliveira: Sim, imagina que Eike Batista está minimamente preocupado com a desigualdade? Ele vive dela, porque vai se preocupar.

Revista Idéias: Mas eu ainda posso dizer que é esse esquema de repressão que mantem a classe trabalhadora paralisada como nos trabalhos dos anos 1980 do Prof. Lúcio Kowarick?

Chico de Oliveira: Não, não precisa de repressão.

Revista Idéias: Essa repressão está internalizada?

Chico de Oliveira: Isso! Há um internalização dos valores burgueses, e isso que conta. A gente faz sociologia assim do cotidiano, eu tinha uma moça que trabalhava aqui comigo, a conversa dela era comprar um carro, eu entrei com meu papo de sociólogo da USP e disse fulana, você sabe o que é comprar um carro? O que ele vai envolver de tua renda? De seu marido? E ela olhou para mim e deu uma resposta que matou a minha argumentação, ela disse: "o senhor não pode ter? Porque que eu não posso?" Ai ela matou, a partir dali eu não disse mais nada, o que ela estava expressando é que ela também é burguesa. Ela não me disse isso com todas as palavras porque ela não era da USP.

Revista Idéias: Mas os valores estão ali.

Chico de Oliveira: Isso, os valores são burgueses.

Revista Idéias: O Professor apresenta algumas reflexões, em suas entrevistas recentes, bastante baseadas em Norbert Elias ${ }^{8}$, no entendimento da sociogênese e a psicogênese como chave explicativa para

\footnotetext{
${ }^{8}$ ELIAS, N.O processo civilizador: uma história dos costumes. Rio de Janeiro: Jorge Zahar Ed., Volume 1. 1994.
} 
a sociedade atual, há uma ciências sociais ou sociologia hoje no Brasil preocupada em traça esse tipo de explicação para os processo sociais?

Chico de Oliveira: Muitos fazem, mas vão fazendo aos pedaços. O Laymert, por exemplo, enfim, mas o que ele faz é unir cultura e tecnologia. Mesmo para nós aquilo que ele produz é quase grego, é preciso ouvir com muita atenção para entender o que ele está dizendo. Isso é a sociedade atual está permeada por um tipo de conhecimento derivado do capital, ela se reproduz assim, por isso Eike Batista não irá pensar em desigualdade, pois ele vive dela.

Revista Idéias: Então, se para o senhor para entender a sociedade como ela está posta é necessário entender sua sociogênese, quais os desafios teóricos metodológicos a serem enfrentados pelos sociólogos?

Chico de Oliveira: Você tem que estabelecer os parâmetros iniciais, o fato de lidarmos com uma sociedade periférica é decisivo, esse é o ponto de partida, e nem sempre foi assim, pois o Brasil entrou na Divisão Internacional do Trabalho, na vanguarda e não na retaguarda, ser produtor de açúcar no século XVII era estar na vanguarda da indústria. Nós fomos os principais produtores de açúcar e isso gerou uma sociedade desigual. De modo que é preciso remontar esses processos para entender a fonte e a origem da desigualdade no Brasil, hoje, entender a origem de nossa condição periférica é o ponto decisivo, estávamos na vanguarda do processo de produção no século XVII, mas não éramos nós que produzíamos o processo técnico capaz de fazer da cana a açúcar.

Revista Idéias: Em relação aos países do BRINCS ${ }^{9}$ ou os países que compõem o Mercosul ${ }^{10}$, o senhor visualiza uma perspectiva de integração sul-sul provoca-nos a pensar em uma periferia mais integrada?

\footnotetext{
${ }^{9}$ Grupo de países considerados emergentes: Brasil, Rússia, Índia, China, e à África do Sul.

${ }^{10}$ Formado por Brasil, Argentina, Uruguai e Paraguai.
} 
Chico de Oliveira: Você acredita nisso? Qual é o grau de integração do Brasil com a Argentina? Qual é o grau com a África do sul? Isso é conversa para boi dormir, ao contrário, o que temos hoje é uma força de trabalho que se tornou móvel devido, e cadê os movimentos contestatórios dos trabalhadores?

Revista Idéias: Em sua visão a mobilidade da força de trabalho ajuda desmobilizar a organização da classe trabalhadora?

Chico de Oliveira: Sim.

Revista Idéias: Porque ora temos esses trabalhadores aqui em São Paulo? Ora na construção da hidrelétrica de Giral, por exemplo?

Chico de Oliveira: Pois é, e isso não cria identidade, essa grande mobilidade desmobiliza os trabalhadores enquanto classe. Nós aqui ficamos aqui esperando que o antigo operariado se manifeste... Bom o antigo operariado é Lula, foi inteiramente absorvido e têm os mesmos valores, esseé o grande aburguesamento que te digo. Se você vasculhar vão encontrar Lula dizendo que é famoso e pobre, gostaria de ser anônimo e rico, ele pertence às categorias que mandam no Brasil hoje, isso não quer dizer que classe dele subiu...

Revista Idéias: Essa classe operária da onde surgiu Lula ainda existe, algum tempo atrás eu vi uma palestra do Prof. José de Souza Martins e ele dizia do desaparecimento dessa classe operaria que gerou o Lula, não sei, se enquanto organização ou mobilização.

Chico de Oliveira: Não... Não existe, porque o desenvolvimento do capitalismo liquida com ela, não é porque foram para outro lugar, não, ela foi liquidada de fato, em outras palavras esse desenvolvimento aburguesa classe operaria, não tem com o que se surpreender... Existe algum grande movimento de contestação nos EUA desde o século passado? Não, esse é um processo de aburguesamento, faz uma extensão apática, então 
aqui... Esse operariado se dissolveu entre o emprego fixo bem remunerado em comparação com a grande massa de trabalhadores, bom, dissolveu entre um carro e uma casa, esse são valores.

Revista Idéias: Minha casa minha vida?

Chico de Oliveira: Que nada, Minha casa minha vida é para os pobres, ele não querem saber em se meter em confusão para salvar o planeta terra, de jeito nenhum.

Revista Idéias: Dado esse programa, alguns analista dizem que os construtores aumentarão o valor do metro quadrado, pois assim alavancariam seus lucros.

Chico de Oliveira: Claro.

Revista Idéias: Sem contar que a população também vai sendo empurrada cada vez mais para longe do centro, do seu trabalho, vão bem mais para a periferia.

Chico de Oliveira: É como o governador de minha terra diria: "De Maracagalha para lá... E bem para lá". Você vai liquidando com os elementos de solidariedade, pois classe social não é apenas um lugar na produção, sem ela a produção não existe de fato, mas só com ela se firma, você tem que ter o lugar da produção e o projeto de classe, projeto de classe não precisa pedir assessoria de sociólogo, projeto de classe é ter um objetivo dentro das condições de dominação vividas. projeto?

Revista Idéias: A classe burguesa no Brasil ainda tem algum

Chico de Oliveira: A burguesia não tinha um projeto diferenciado, a questão dela era conseguir a dominação, e a dominação você vai fazendo nas condições que são dadas nesse estatuto periférico, esse estatuto retira a áurea civilizatória, você 
não domina exatamente o capitalismo, você é também dominado, isso é o estigma da sorte, não é só porque tivemos escravos. Os EUA também tiveram, não é atoa a parte pior dos Estados Unidos estava no sul exatamente onde o escravismo vigorou ao ponto de ter fazenda de criação de escravo, o que é uma coisa que nem dá para pensar. Apesar disso os Estados Unidos conseguiram tornarse uma sociedade menos desigual, não é mais desigual, mas é menos desigual, a Guerra civil americana foi importante para isso, nós não tivemos guerras desse gênero, mas o fato de que éramos os principais comerciantes de reservas de força de trabalho fez com que tenhamos o que você vê hoje, você não precisa, por exemplo, colocar anuncio nos jornais a procura de uma empregada doméstica (risos) basta as pessoas saberem que eu estou precisando de uma empregada e aqui a fila será enorme, agora depois de muita luta é que chamado que os direitos trabalhista começam ser aplicado as empregada, por exemplo, essa é a nossa sociedade capitalista e desigual. 